\title{
A Risk Scenario for Small Businesses in Hurricane Sandy Type Disasters
}

\author{
Arthur H. Hendela \\ New Jersey \\ Institute of \\ Technology \\ ahh2@njit.edu
}

\author{
Murray Turoff \\ Centre for Integrated, Emergency \\ Management, University of \\ Agder, Norway and NJIT \\ murray.turoff@gmail.com
}

\author{
Starr Roxanne Hiltz \\ Centre for Integrated, \\ Emergency Management, \\ University of Agder, \\ Norway and NJIT \\ roxanne.hiltz@gmail.com
}

\author{
Jerry L. Fjermestad \\ New Jersey Institute of \\ Technology \\ jerry.l.fjermestad@njit.edu
}

\section{Abstract}

This research uses a series of surveys followed by mathematical modeling to help discover risk factors, mitigating actions, and the highest return scenarios as a basis for a low-cost business continuity/disaster recovery plan. The surveys use a Delphi study format in order to rank a base list of risks and mitigating actions and to supplement those lists with ones added by the participants. Survey results are analyzed and presented back to the group for a second round of ranking and supplementing the risk/action categories. This paper describes the top ten risks and high value scenario for small business interruptions as determined by a Delphi survey of small businesses affected by Hurricane Sandy. The highest ranked risk is loss of business reputation. The research then uses Cross Impact Analysis and Interpretive Structural Modeling to determine the risk interactions and the highest valued scenario for which to prepare.

\section{Introduction}

Hurricane Sandy, which struck the New Jersey area on October 29, 2012, demonstrated weaknesses and vulnerabilities even in the best Business Continuity/Disaster Recovery plans (BC/DR). The storm caused concurrent widespread power loss, water and wind damage, and a lack of motor fuel. Small businesses were especially vulnerable to interruption due to their limited budgets to prepare and implement a plan [1]. Uncovering additional interruption causes and how they interrelate is complex given bounded rationality and limited knowledge [2].

A great deal of planning should go into the preparation for reacting to a situation that can interrupt business operations by either natural or human origin. Currently, "hundred year" natural disasters, such as Super Storm Sandy, seem to be happening at a greater frequency. Today the "unthinkable" world of dirty bombs, bio-terrorism, thousand year floods, rising ocean levels, multiple hurricanes, and super-volcanoes have become very thinkable. We need to determine the most serious threat risks. Once these risks are known, we then use modeling to determine the highest impact scenarios to prepare on a limited budget. For the purpose of this paper we want to focus on finding the highest impact risks for small business, see how they influence one another, and then determine the highest impact risks for which to prepare.

The amount of data that can be collected at a scene of a natural disaster can be overwhelming. The ability to process this information is hindered by short term memory. Various techniques have been used to simplify the complexity and the number of inputs [3]. One technique to reduce complexity and provide structure to the interpretation of the information is mathematical modeling [4].

This study gathered base information for conversion into mathematical form by asking small business owners and emergency preparedness experts to rank the importance of risk and mitigation items which might cause a business interruption across sixteen categories. The cause of the interruption might be a weather event such as Hurricane Sandy or manmade events such as legal problems or civil unrest. Data was collected through an online Delphi study [5]. A set of risk items was then paired and one item's influence on another was estimated by an expert panel familiar with the process. The results of the pairing were put into a mathematical program to measure the influence of one item on another. This process is known as Cross Impact Analysis [6]. The final step was to graphically determine sets of risks that were tightly coupled into scenarios or Macro Events using Interpretive Structural Modeling [7].

Creating scenarios is a popular approach for planning that depicts unusual situations to assist those who are not experts in the complexity of creating plans or understanding the impact that those plans will have on future events [8]. The method we used for the creation of scenarios was Interpretive Structural Modeling (ISM). According to Sushil, ISM is a 
process that transforms unclear mental models into a visible, well-defined model that can be used in many ways [9]. The technique is interpretive as it uses the judgment of group members to determine how and if variables are related. It is structural in the sense that the interrelationship between variables evolves into a simplified and more organized form. It is a model as the output becomes a graphical representation of the structure and relationships between the variables [10].

In the earliest use of ISM, Warfield analyzed complex, rapidly changing societal systems [4]. He did this by using a process of collective exploration to increase intellectual productivity. The increase in productivity was achieved by separating the mental activity into areas that were best suited to the individual. The group decided how sets of variables interacted with one another. The output of the group process was a visual model of interaction that was more easily understood. This simplification of complexity has helped ISM's applications become more widespread.

There are many examples of the use of ISM and Cross Impact Analysis in the literature. For example, Malone showed the application of ISM to structure personal values that created barriers to investment in a city [11]. Borade and Bonsad applied ISM to supply chain management to improve Indian business performance via Vendor Managed Inventory (VMI) [12]. Guo, Li, and Stevens used ISM to analyze technology use motivations in students [13]. Ravi used ISM to determine the barriers to eco-friendly packaging in an Indian computer manufacturer [14]. An Indian construction company used ISM to determine the most influential factors for worker safety and environmental consciousness [15]. Whereas this study used ISM to assess risk factors for business interruption, Wu,et al. used ISM to assess risk factors in two Taiwanese, offshore pipeline projects [16]. Bañuls, Turoff, and Hiltz applied the technique in combination with Cross Impact analysis to develop collaborative scenarios in Emergency Preparedness [17]. These scenarios were used to enhance the understanding of the factors that were encountered by response teams.

The way we understand and analyze a crisis situation is to investigate and relate the events. Thus scenario development is an appropriate way to try to plan future actions and to promote understanding with respect to potential crisis situations. However, a scenario alone is insufficient in that we have no criteria to establish the validity of a single scenario about an event that has not occurred [18].

In the remainder of this paper, we first present a more extensive review of the three methods used, as they relate to the procedures in this study. The methods and procedures are then described, in two parts. Because this study used several different measures, we first describe the overall flow of steps, followed by details of the research method. The paper ends with results and conclusions.

\section{Literature Review}

Too often decision makers become infused with the idea that what worked in the past to bring about a success will work just as well in the future [19]. The process to create scenarios [20] appears to bring out unforeseen consequences that cause a reexamination of basic assumptions. Scenarios can then be improved to the point of becoming action plans [21] with variations that reflect new alternatives that need to be considered [22]. Clemons [23] puts it very well: "One of the greatest limitations to strategic change is the considerable number of things successful incumbents know about their industry that unfortunately are no longer true.”(Page 65)

\subsection{Involving the Small Business Owner}

Where traditional research looks to create generalizations based on experimental results, this research aims to "produce and apply knowledge of tasks or situations in order to create effective artifacts” to improve practice [24].

To create the basis for a disaster planning model, we use small business owners, a community of practice that cuts across different types of businesses, to assist in this iterative process. It is often the case that the creation of the business continuity/disaster recovery plan falls on the owner of the business or a set of individuals that are affiliated with different organizational units or groups within a business. Each person is responsible for a different aspect of the plan grouped into a professional network.

Table 1 Research Model Evaluation Steps with Objectives and Methods

\begin{tabular}{|l|l|l|}
\hline $\begin{array}{l}\text { Evaluation } \\
\text { Step }\end{array}$ & \multicolumn{1}{|c|}{ Objective } & \multicolumn{1}{|c|}{ Method } \\
\hline $\begin{array}{l}\text { Delphi } \\
\text { Method }\end{array}$ & $\begin{array}{l}\text { Determine event } \\
\text { set }\end{array}$ & $\begin{array}{l}\bullet \text { Surveys } \\
\bullet \text { Expert } \\
\text { opinion }\end{array}$ \\
\hline $\begin{array}{l}\text { Cross } \\
\text { Impact } \\
\text { Analysis }\end{array}$ & $\begin{array}{l}\text { Determine } \\
\text { interaction } \\
\text { probabilities of } \\
\text { the events }\end{array}$ & $\begin{array}{l}\bullet \text { Surveys } \\
\text { Modeling } \\
\text { software }\end{array}$ \\
\hline $\begin{array}{l}\text { Interpretive } \\
\text { Structural } \\
\text { Modeling }\end{array}$ & Find scenarios & $\begin{array}{l}\text { Modeling } \\
\text { software }\end{array}$ \\
\hline
\end{tabular}


We use a blending of several evaluation and analysis approaches to create the basis for the Business Continuity/Disaster Recovery (BC/DR) plan. The three approaches that are used are the Delphi Method, Cross Impact Analysis, and Interpretive Structural Modeling. Blending multiple methods to perform research is not without precedent. Vaishnavi and Kuechler's work [25] promotes the idea of using multiple methods to create artifacts when using the design science approach. The use of multiple methods blended together has been advocated as beneficial by both Mingers [26] and Nunamaker, Chen, and Purdin [27]. The model shown in Figure 1 depicts the steps involved in this study. At each level, information gathered in one phase drives the next phase. Our goal is to stimulate creativity and reflective thinking on the part of the participants about situations that can only be described, assessed, and planned for on the basis of detailed qualitative considerations.

\subsection{The Delphi Method}

The Delphi Method was developed in the 1950s at the RAND Corporation to obtain expert input on a particular problem while allowing the participants to remain anonymous. These expert panels are given questionnaires and participate in answering them at a time and place convenient to them. The technique is particularly useful in cases where the expert panel is dispersed over a wide geographic area [28].

The method utilizes a series of preselected questions over several rounds where each participant may suggest additional items. After each set of questionnaires is completed, a facilitator summarizes the expert's input and then redistributes the summary with another round of questions [29]. The experts can then revise their answers. The process continues for a set number of rounds. In this study, two rounds were used, after which no further suggestions were made for new risk or action items.

The Delphi Method has been deemed suitable for domains that have the following properties:

- Subjective expertise and judgment inputs,

- Complex, large, multidisciplinary problems with considerable uncertainty,

- Possibility of unexpected breakthroughs,

- Causal models cannot be built or validated,

- Particularly long time frames,

- Opinions from a group where anonymity is deemed beneficial.

Virginia Commonwealth University (VCU) uses the Delphi Method for several reasons not listed above. First, the method is used when subjects are spread out over several states making face to face interviews not cost effective. This is certainly the case for this study where the participants are throughout the New Jersey/New York City region affected by Hurricane Sandy. Second, VCU uses the method when the participants are busy professionals who need flexibility to participate. The small business owners used in this study fit this requirement as well [30].

\subsection{Cross Impact Analysis (CIA)}

Cross impact analysis (CIA) consists of a set of related methodologies that predict the occurrence probability of a specific event that also impacts the occurrence or non-occurrence of another event on the original event's 0.5 probability status by estimating a new probability value. This generates linear measures of influence between events [31]. The method was developed in 1966 by Theodore Gordon and Olaf Helmer based on discussions about a simple research question, "can forecasting be based on perceptions about how future events may interact [32]?”

A CIA model has three types of events. They all are given an initial probability of 0.5 which is the zero point of probability. At 0.5 there is an equal chance of an event occurring or not occurring. There is also no assumption of influence over other events.

The first type of event is the initial conditions at the start of the period during which the disaster happens. These are things that reflect significant aspects of possible mitigation or preparedness that are the results of actual investments in infrastructure such as reinforcing dams or the enacting of new policies such as improving building codes to minimize water damage. These initial condition events can influence the probability of the dynamic events or the outcome events. The dynamic events are the ones that can change values of probability based on the initial conditions and can influence outcome events during the period between the start of the disaster until the beginning of recovery operations. The outcome events are the ones that have a final value of probability based upon the changes to the other types of events.

\subsection{Interpretive Structural Modeling (ISM)}

As stated previously, Interpretive Structural Modeling (ISM) is a process that transforms unclear mental models into a visible, well-defined model that can be used in many ways [9].

Bañuls, Turoff, and Hiltz applied the technique in combination with CIA to develop collaborative scenarios in Emergency Preparedness [17]. These scenarios were used to enhance the understanding of the factors that were encountered by response teams.

In combination with CIA, the ISM approach allows researchers and practitioners, in our case small 
business owners and planners, to take the output of the influence graph and obtain a plausible snapshot of the future with interactions between critical events [7].

\subsection{Combining the Delphi Method, Cross Impact Analysis, and Interpretive Structural Modeling}

Combinations of the Delphi Method, Cross Impact Analysis, and Interpretive Structural Modeling have helped to simplify the prediction of future events by easing complexity. Many studies have been performed that used one of these methods at a time. Additional results have been captured using combinations of the approaches. Some studies have used Delphi, CIA, and ISM while others have used one or more of these approaches with different mathematical analysis techniques. Valmohammadi and Dashti used a literature search instead of a Delphi method to identify his factors affecting entry into e-commerce markets [33]. Huega, Bañuls, and Turoff used a combination of CIA and ISM and a scenario generator to determine the effect of "Cause events" on "Result events" while modeling risks at a hypothetical European metallurgical plant [34].

Bañuls and Turoff were the first to explore the combination of the Delphi Method, CIA, and ISM [7]. The use of expert opinion from the Delphi survey combined with the mathematical techniques afforded the opportunity to assess the impact of the technology set as a whole. Cross Impact Analysis was used to create the cross influence of one technology with another. The strength of adding ISM to the established Delphi and CIA methods was to create a graphical depiction of the high order interactions as a means to display event scenarios. The ability to see the scenarios graphically, in addition to being in a numeric table, allows decision makers to more clearly substantiate their thought process and decision [7].

In a pair of related studies, application of the CIAISM approach was used to assess the impact of a series of negative events against Critical Infrastructure (CI) [35, 36]. Infrastructure elements may be considered critical when they provide a function that is essential for routine processes and for which no rapid substitute exists. Sixteen CI elements such as "water supply undrinkable" and "No Gasoline" were selected for this assessment. Experts were asked to provide the input for the Cross Impact Analysis in a series of surveys that asked for probabilities of how each negative event interacted with each other one. Only areas with which an expert was familiar were judged. The resultant model of influences was deemed reasonable [35]. A follow-up paper examines the cascading effects of the critical infrastructure failures during disasters using scenario software currently under development [36].

The current research builds on the 2014 CI study [35] to uncover relationships in a set of risks and mitigating actions that small business owners can use as a foundation of a business continuity/disaster recovery plan. This process, which combines the Delphi Method, CIA, and ISM methods, will hopefully ease the planning burden on a business with limited resources. At the same time it is hoped to provide a learning experience that can lessen a disaster's effects on each individual involved with this study.

\section{Research Model and Method}

The general structure of the modeling process is shown in Figure 1.

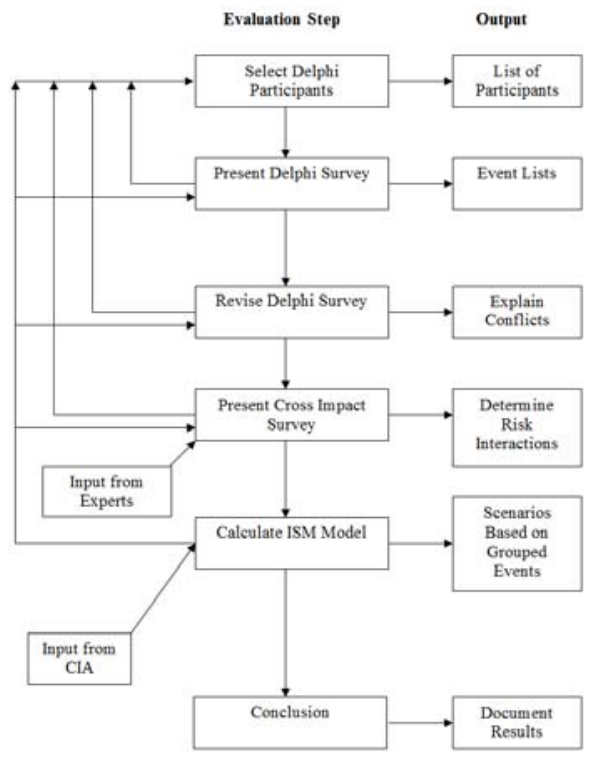

Figure 1 Research model flow.

\subsection{Selecting Delphi Participants}

The Delphi method [37] is well established and is a proven method for gathering information that is either difficult or impossible to gather with other techniques. In addition to posing questions anonymously to the selected group and then summarizing the results for the next round, we extend the traditional Delphi Method with a process known as snowballing [38]. Snowballing is the use of current participants to help find new participants. The researcher reviewed the suggested participant on a case by case basis to determine if he/she met the qualifications and if qualified, allowed them to join the research [29].

The participants for the Delphi and subsequent phases were selected from personal and professional contacts. The participants were selected from small 
business owners or other managers that had business responsibility for business continuity and disaster recovery. We looked for business owners and workers that had been in business for at least three years to ensure that they were in business at the time of Hurricane Sandy. Potential participants were identified from the rolls of several New Jersey based chambers of commerce. Approximately 4500 email contacts were made in order to reach the first round participant number of 60 respondents, completed between February 26, 2015 and April 1, 2015. The second round was completed by 42 of the initial participants between June 1, 2015 and July 2, 2015.

\subsection{Present Delphi Survey}

Each qualified participant was given access to the Delphi surveys and instructions on how to participate. Each of the participants was given two lists. The first was a list of risks divided into sixteen categories based on the recent study by Turoff, et al. [35] and the recently published New York City Sandy resiliency report [39]. The second list was a set of mitigation actions that can lessen the effect of the threats. This list is based on Henry's categories [40]. These initial lists were given to the participants via the online survey system where they were asked to rank each item's importance, add to the list, delete from the list, and comment on the list. Once the comment period passed, the researcher consolidated the comments and reissued the lists to the participants. This aggregated set was sent to the group for a second evaluation round. The group performed the following activities on the revised sets:

1. Provide an indication of relative importance via a Likert-scale rating survey.

2. Remove risk/mitigation action items that are not relevant for further study. Comment on why the item should be removed.

3. Add events/mitigation items not considered in the base sets. Comment on why the item should be added.

The participants performed their tasks anonymously. Only the lead researcher knew who commented. Through the analysis of the input, we identified factors that were the most relevant to the study. These results helped to improve the factors, instructions, and guided the next iteration [41].

\subsection{Revise Delphi Survey}

Forty-two of the sixty first round participants returned to participate in Round 2. Before beginning
Round 2 the participants viewed a summary of Round 1 results ahead of the actual Round 2 survey. The specifics of the results were in the form of text describing the number of respondents, the business categories covered by the respondents, and the most active risk and action categories as ranked by the Round 1 participants. Following the text summary were numeric charts showing the counts and average response rankings for each of the sixteen major risk and mitigation action categories.

The group of participants read the directions for round two and began to take the survey. The list of risk and action events were revised based on the additions to the base sets used for Round 1 . The revised lists underwent a second evaluation in the same manner as the first. Relative probabilities were assigned by the participants and the list modified based on their input. Because no new risk or action items were added during Round 2, the Delphi study portion of the research was considered complete.

The list of risk/action categories and the number of individual items surveyed is shown in Table 2.

Table 2 Table of Risk/Action Categories and Number of Items Surveyed over Rounds 1 and 2

\begin{tabular}{|l|c|c|}
\hline $\begin{array}{c}\text { Round 1 Result } \\
\text { Category }\end{array}$ & $\begin{array}{c}\text { Number } \\
\text { of Risks }\end{array}$ & $\begin{array}{c}\text { Number } \\
\text { of } \\
\text { Actions }\end{array}$ \\
\hline Financial & 31 & 16 \\
\hline Fire & 6 & 6 \\
\hline Flood & 9 & 6 \\
\hline Government & 10 & 3 \\
\hline Health & 8 & 4 \\
\hline Legal & 18 & 9 \\
\hline Personnel & 12 & 7 \\
\hline Product & 11 & 18 \\
\hline Property & 10 & 7 \\
\hline Security & 4 & 6 \\
\hline Supply Chain & 10 & 6 \\
\hline Technology/Data & 20 & 24 \\
\hline Terrorism & 3 & -- \\
\hline Transportation & 7 & 3 \\
\hline Utility & 8 & 5 \\
\hline Weather & 5 & 14 \\
\hline TOTAL: & 172 & 134 \\
\hline
\end{tabular}

Note: Terrorism actions were not part of this study as it was considered to be the purview of government and not the small business. 


\subsection{Present Cross Impact Survey}

After two rounds of the Delphi surveys, the values assigned by the rankings were transformed to input suitable for Cross Impact Analysis by a panel of experts. A set of top ranked risks were selected and items were divided into three categories. Five items were designated as Input Events. Fifteen items were designated as Dynamic Events. Five were designated as Outcome Events.

The base event probabilities for the event set, known as $P(i)$, were set to a value of 0.50 . The influence probabilities of the events paired two at a time, known as $C(i, j)$ were determined by the average values of the influence probabilities. We only asked participants to give probabilities for areas in which they considered themselves competent [35]. The output from the calculation evaluates the Gamma variable, $G(i)$, which takes into account the impact of events that have not been explicitly specified. $G(i)$ is the constant which is a linear influencing factor which compares to the other linear influencing factors the other $\mathrm{N}-1$ events generated by the cross impact method. The finite set of risk events which we used to determine the Cross Impact influence probabilities was, by definition of finite, incomplete. Other factors that were not in the explicit list under study may have influenced a particular event and either mitigated or exacerbated it. The calculation of the Cross Impact probabilities was based on the probability that a particular event occurred, $P(i)$, the probability of the $i$-th event given that an influencing event, $j$, was certain to occur $\left(R_{i j}\right)$ and the probability of the $i$-th event given that an influencing event, $j$, was certain to not occur $\left(S_{i j}\right)$.

The calculation of the influence probabilities does not balance unless non-explicitly specified events are taken into account. The $G(i)$ variable is used to balance the equations. A high value of $G(i)$ shows that the events under study have not taken into account many possible outside influences. A small value of $G(i)$ shows that the events under study are more complete and take into account more of the possible influences on an event [6]. The output values from the CIA model are the input for the ISM scenario model.

\subsection{Calculate ISM Model}

ISM merges with CIA by taking the $C(i, j)$ values from CIA and using them to create directed graphs that show the influence of one event on another. The absolute values of all $C(i, j)$ 's are put into an ordered list from highest to lowest. A cutoff threshold point is chosen to allow approximately $10 \%$ of the values to be included in the model. For this study the threshold values were 0.80 and 1.00 . The higher threshold value shows a stronger influence between items. A graph is made of the items to determine if any internal cycles exist between events. The grouping of the event cycles represent mini-scenarios that can be treated as a single, dynamic Macro Event. A Macro Event is said to occur when and only when all events in an event chain occur. Choosing approximately $10 \%$ of the values for ISM graph analysis allows the researcher and ultimately the business owner to concentrate on the highest impact scenarios. Using a cut-off value much higher than $10 \%$ includes too many events and does not allow for the proper emphasis on the highest priority scenarios [35].

Table 3 Event Numbers Assigned to ISM graphs

\begin{tabular}{|c|l|l|}
\hline $\begin{array}{c}\text { Event } \\
\text { Number }\end{array}$ & Code & \multicolumn{1}{c|}{ Meaning } \\
\hline 1 & I1 & $\begin{array}{l}\text { Computer server not fully } \\
\text { backed up }\end{array}$ \\
\hline 2 & I2 & Fires underway \\
\hline 3 & I3 & Hurricane in area \\
\hline 4 & I4 & $\begin{array}{l}\text { Business continuity plan not } \\
\text { tested }\end{array}$ \\
\hline 5 & I5 & $\begin{array}{l}\text { Local government not } \\
\text { functioning }\end{array}$ \\
\hline 6 & DE1 & Electricity cut off \\
\hline 7 & DE2 & No communication networks \\
\hline 8 & DE3 & Computer hardware fails \\
\hline 9 & DE4 & $\begin{array}{l}\text { Personnel not available } \\
\text { during an emergency }\end{array}$ \\
\hline 10 & DE5 & $\begin{array}{l}\text { Violent crime committed by } \\
\text { employee during work hours }\end{array}$ \\
\hline 11 & DE6 & $\begin{array}{l}\text { Backup power supply not } \\
\text { available }\end{array}$ \\
\hline 12 & DE7 & Access to facility forbidden \\
\hline 13 & DE8 & Telephones out of service \\
\hline 14 & DE9 & Internet connectivity lost \\
\hline 15 & DE10 & $\begin{array}{l}\text { Increased lead time due to } \\
\text { storm or other event }\end{array}$ \\
\hline 16 & DE11 & Roads flooded \\
\hline 17 & DE12 & Gasoline in short supply \\
\hline 18 & DE13 & Roads clogged with traffic \\
\hline 19 & DE14 & $\begin{array}{l}\text { Crime rate increase near place } \\
\text { of business }\end{array}$ \\
\hline 20 & DE15 & Product in transport destroyed \\
\hline 21 & O1 & $\begin{array}{l}\text { Loss of documents and } \\
\text { company materials/records }\end{array}$ \\
\hline 22 & O2 & Business reputation tarnished \\
\hline 23 & O3 & Computer data lost \\
\hline 25 & O4 & Raw material cost increase \\
\hline & Raw materials contaminated \\
\hline
\end{tabular}




\subsection{Calculating Risk}

Data collection from the small business workers was performed using a series of surveys hosted on SurveyMonkey.com. Approximately 4500 emails were sent to reach the first round response total of sixty surveys. After two survey rounds, the mean for each item was calculated across all risk categories using a weighted average. This weighted average was calculated by summing the multiplication of the number of responses in each risk level times the weighting value, divided by the total number of responses for that risk item. Table 3 shows the event list used for the ISM model. The weighting values and the Risk Level used in the Likert scale are shown in Table 4. A similar scale and calculation was used for Action items.

Table 4 Risk Judgment Scale

\begin{tabular}{|l|c|}
\hline \multicolumn{1}{|c|}{ Risk Level } & Weighting Value \\
\hline Critically Important & 5 \\
\hline Very Important & 4 \\
\hline Somewhat Important & 3 \\
\hline Minor Importance & 2 \\
\hline No Importance & 1 \\
\hline No Judgment & 0 \\
\hline
\end{tabular}

Note: "No Judgment" votes were allowed but were not used in the calculation of averages.

\section{Results}

\subsection{Ranking of Risks}

The most important risks were determined by ranking the risks by the weighted mean value, as shown in Section 3.6 above. The top 10 risks are shown in Table 5 . The table shows the survey round number (R), the risk category, risk item text, the number of respondents that ranked the item, the weighted mean value, and the standard deviation. Based on these results, the small businesses were most concerned about losing their business reputation. This result is quite understandable. Physical damage can be repaired. Business property can be rebuilt. Office equipment can be replaced. Years of building a reputation can be destroyed quickly. Once your reputation is tarnished, it is nearly impossible to regain it.

The energy giant, Enron, supposedly used innovative tracing techniques to lure investors. The stock soared in the 1990's. When large scale malfeasance inflated earnings, the reputation of the company was irreparably damaged. Not only did the company go bankrupt, but its large accounting firm, Arthur Andersen, was forced to surrender its operating licenses and was held criminally negligent. Enron executives were also convicted. Neither Enron nor Arthur Andersen exist today [42].

Table 5 Top 10 Round 1 Plus Round 2 Consolidated Risk Results Across All Categories

\begin{tabular}{|c|c|c|c|c|c|}
\hline $\mathbf{R}$ & $\begin{array}{c}\text { Risk } \\
\text { Category }\end{array}$ & Text & $\mathbf{N}$ & Mean & $\begin{array}{l}\text { S. } \\
\text { D. }\end{array}$ \\
\hline 1 & Financial & $\begin{array}{l}\text { Business } \\
\text { reputation } \\
\text { tarnished }\end{array}$ & 53 & 4.42 & 1.1 \\
\hline 2 & Fire & $\begin{array}{l}\text { Loss of } \\
\text { documents and } \\
\text { company } \\
\text { materials/ } \\
\text { records }\end{array}$ & 41 & 4.29 & 0.8 \\
\hline 1 & Utility & $\begin{array}{l}\text { Electricity cut } \\
\text { off }\end{array}$ & 49 & 4.29 & 0.9 \\
\hline 1 & $\begin{array}{l}\text { Technology/ } \\
\text { Data }\end{array}$ & $\begin{array}{l}\text { Computer data } \\
\text { lost }\end{array}$ & 52 & 4.06 & 1.1 \\
\hline 1 & $\begin{array}{l}\text { Technology/ } \\
\text { Data }\end{array}$ & $\begin{array}{l}\text { Computer virus } \\
\text { attacks network }\end{array}$ & 51 & 4.06 & 1.2 \\
\hline 1 & $\begin{array}{l}\text { Technology/ } \\
\text { Data }\end{array}$ & $\begin{array}{l}\text { No } \\
\text { communication } \\
\text { networks }\end{array}$ & 50 & 4.06 & 1.0 \\
\hline 1 & $\begin{array}{l}\text { Technology/ } \\
\text { Data }\end{array}$ & $\begin{array}{l}\text { Computer } \\
\text { server not fully } \\
\text { backed up }\end{array}$ & 51 & 4.04 & 1.1 \\
\hline 1 & $\begin{array}{l}\text { Technology/ } \\
\text { Data }\end{array}$ & $\begin{array}{l}\text { Computer } \\
\text { system hacked }\end{array}$ & 51 & 4.02 & 1.2 \\
\hline 1 & $\begin{array}{l}\text { Technology/ } \\
\text { Data }\end{array}$ & $\begin{array}{l}\text { Cyber-attack on } \\
\text { computer } \\
\text { infrastructure }\end{array}$ & 50 & 4.02 & 1.3 \\
\hline 1 & Utility & $\begin{array}{l}\text { Backup power } \\
\text { supply not } \\
\text { available }\end{array}$ & 47 & 4.02 & 1.0 \\
\hline
\end{tabular}

\subsection{Development of the ISM-Based Scenarios}

Figure 2 shows the development of the ISM cycles between events. Cycles are developed by locating events that have links between them. Notice that the graph lines between events 7 and 14 go back and forth. This shows a direct influence cycle where event 7 influences event 14 and vice versa. Once those two events are merged into the beginning of the Macro Event, notice how events 13, 9 and 8 are chained together back into the event set 7 and 14 . 


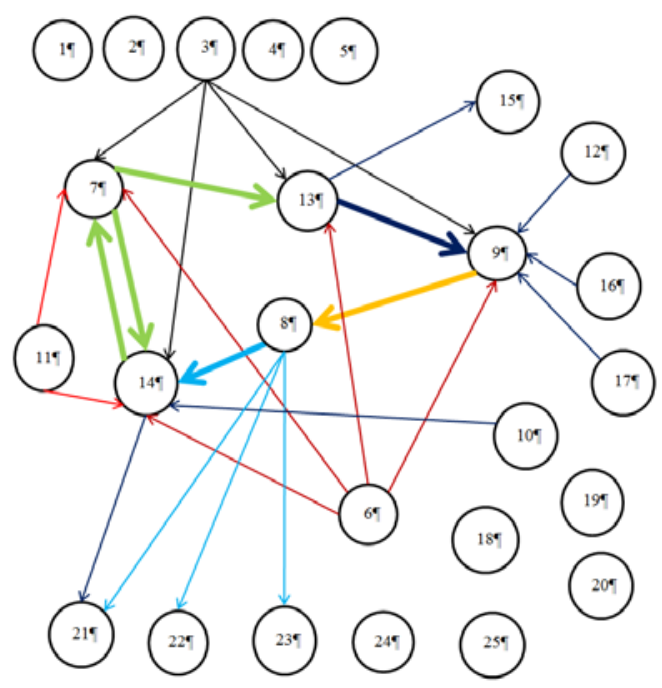

Figure 2 Development of the MACRO X event cycle for the input hurricane event at the $\left|C_{i j}\right|>1.00$ level.

These two chains represent the creation of a Macro Event or scenario. Figure 3 shows the Figure 2 influence graph with the values collapsed into a Macro Event, $((7,14), 13,9,8)$.

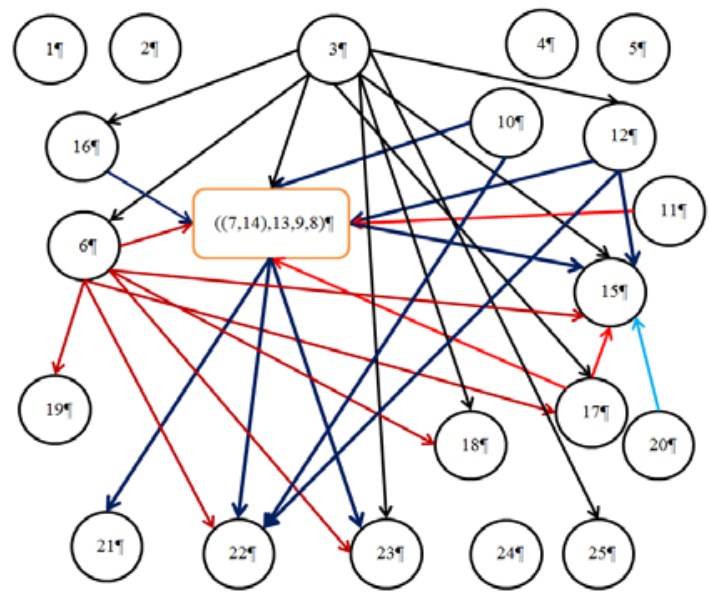

Figure 3 Influence of the hurricane event, event 3 , on all events at the $\left|C_{i j}\right|>1.00$ level. This shows the combination of events of the second collapse to form the Macro Event $((7,14), 13,9,8)$.

Figure 3 shows the influence of the Hurricane event, event 3, on the Macro Event, Events $((7,14), 13$, $9,8)$ on the tarnishing of the business reputation, event 22. The Macro Event is comprised of the events shown in Table 6. The tightest coupled events are events 7-No communication networks and 14- Internet connectivity lost. These are shown as the two events inside of the inner parentheses. The influence between these two events is well defined. If there is no communications network then internet connectivity is lost. The reverse is also true. If internet connectivity is lost, a very plausible reason for that is that there is no communications network. At the very least, part of that communications is cut off.

The other three events outside of the inner parentheses mean that events 7 and 14 influence them in a cyclic manner. The combination of no communications network and no internet connectivity influences Event 13-Telephones out of service. The communications backbone is unavailable to support the telephone calls.

Table 6 Macro Event Risks

\begin{tabular}{|c|l|l|}
\hline $\begin{array}{c}\text { Event } \\
\text { Number }\end{array}$ & Code & \multicolumn{1}{c|}{ Meaning } \\
\hline 7 & DE2 & No communication networks \\
\hline 14 & DE9 & Internet connectivity lost \\
\hline 13 & DE8 & Telephones out of service \\
\hline 9 & DE4 & $\begin{array}{l}\text { Personnel not available during } \\
\text { an emergency }\end{array}$ \\
\hline 8 & DE3 & Computer hardware fails \\
\hline
\end{tabular}

Event 13-Telephones out of service influences Event 9-Personnel not available during an emergency. There may be any number of reasons why personnel becomes unavailable to help in recovery including limited or no communications and telephone services. It may become impossible to contact key personnel to come to work and help the recovery process. The macro event comes full circle when Event 9 influences Event 8-Computer hardware fails. Without the communications network, proper cloud backup would not be possible nor would remote access be available to check or shut down hardware.

In Figure 3, event 22 has the most other events (four) pointing to (influencing) it. One is the macro event containing five of the original events and events 6-electricity cut off, 10 -violent crime committed by an employee, and 12- access to facility forbidden. Although event 22-Business reputation tarnished may influence other outcome events such as event 23Computer data lost, outcome events are not evaluated for their influence on one another when using the Cross Impact Analysis approach.

\section{Conclusions}

Small businesses need to plan and react to business interruptions for which they may have little preparation. An essential step in creating an emergency preparedness plan is to determine the risks that the business may face. This research provides a list of 
sixteen categories to help focus the planning process on areas of concern. The next step after determining what high level disaster may occur, such as fire or flood, is to identify what might specifically cause damage. Inside of these sixteen risk categories we provide the business person a base set of one hundred seventy-two risk items and one hundred thirty-four preparation/action items to consider. Some items may not be applicable to a particular business. The list may spur ideas for items not on the base lists. Other items are what is exactly needed, but might not have been considered prior to this research.

Once the risks are assessed, priorities need to be set on how to prepare. Instead of using "gut feel" techniques for what is needed, the opinions of fellow business owners are available to help set the priorities. These sorted, ranked results help clarify the highest impact risks, both by category and across all categories.

There are many different risk items to select and prioritize. This research helps the small business to set those priorities by quantifying how one risk may influence another. Thinking about how one risk influences another is tedious and complex. This research quantifies the influence of one risk on another using subjective probability estimates. These estimates are used in the Cross Impact Analysis software to mathematically quantify what combinations of risks should be considered for preparation. Output from the program can be sorted by the highest risk values.

Once risk interactions are quantified, this research helps find groups of interactions that represent the highest value items for which to prepare. The method combines individual events into scenarios. These scenarios represent the most concentrated use of limited budgets for mitigating small business interruption.

\section{Contributions}

There are two anticipated main contributions of this work. The first is the development of the Cross Impact and Interpretive Structural Model that can potentially change how Business Continuity/Disaster Recovery (BC/DR) plans are created. No prior study has been undertaken that uses the combination of the Delphi Method, Cross Impact Analysis, and Interpretive Structural Modeling to create a basis for a small business BC/DR plan. Understanding the interaction between risk factors and not just their summarized importance will further clarify how BC/DR plans can be optimized for better recovery.

Secondly, planning personnel will be able to optimize the allocation of budget resources as the CIA/ISM model provides the ability to rank potential improvements based on $\mathrm{C}_{\mathrm{ij}}$ values and ISM scenarios. The model results will spur new discussions on how best to improve BC/DR plans from ever changing risks.

\section{Acknowledgements}

This paper is based on a dissertation that was completed in the Spring of 2016. The dissertation is available from the NJIT library at http://library.njit.edu/etd. We thank the other members of the dissertation committee for their valuable advice Jerry Fjermestad, Julian Scher, and Thomas Wilkin. We also thank all of the small business people who participated in this study. We thank the University of Agder, Norway for their travel support of Drs. Turoff and Hiltz to attend the HICSS conference.

\section{References}

[1] J. Manuel, "The Long Road to Recovery," Environmental Health Perspectives, vol. 121, pp. 153159, 2013.

[2] H. Simon, "Bounded Rationality and Organizational Learning," Organization Science vol. 2, pp. 125-134, 1991.

[3] G. Miller, "The Magical Number Seven, Plus or Minus Two: Some Limitations on Our Capacity for Processing Information," Psychology Review, vol. 63, pp. 81-87, 1956.

[4] J. Warfield, Societal Systems. New York, NY: Wiley, 1973.

[5] M. Turoff, "The Design of a Policy Delphi," Technology Forecasting and Social Change, vol. 2, pp. 149-171, 1970.

[6] M. Turoff, "An Alternative Approach to Cross Impact Analysis," Technology Forecasting and Social Change, vol. 3, pp. 309-339, 1972.

[7] V. Bañuls and M. Turoff, "Scenario Construction Via Delphi and Cross Impact Analysis," Technological Forecasting \& Social Change, vol. 78, pp. 1579-1602, 2011.

[8] K. Go and J. M. Carroll, "The Blind Men and the Elephant: Views of Scenario-Based System Design," Interactions, vol. XI.6, pp. 45-53, 2004.

[9] Sushil, "Interpreting the Interpretive Structural Model," Global Journal of Flexible Systems Management, vol. 13, pp. 87-106, 2012.

[10] A. Singh, M. Singh, and B. Sharma, "Modeling of Knowledge Management Technologies: An ISM Approach," The IUP Journal of Knowledge Management, vol. 11, pp. 41-55, 2013.

[11] D. Malone, "An Introduction to the Applications of Interpretive Structural Modeling," Proceedings of the IEEE, vol. 63, pp. 397-404, 1975.

[12] A. Borade and S. Bonsad, "Interpretive Structural Modeling-based Framework for VMI Adoption in Indian Industries," International Journal of Advanced 
Manufacturing Technology, vol. 58, pp. 1227-1242, 2012.

[13] Z. Guo, Y. Li, and K. J. Stevens, "Analyzing Students' Technology Use Motivations: An Interpretive Structural Modeling Approach," Communications of the Association for Information Systems, vol. 30, pp. 199224, 2012.

[14] V. Ravi, "Analysis of Interactions Among Barriers of Eco-Efficiency in Electronics Packaging Industry," Journal of Cleaner Production, vol. 101, pp. 16-25, 2015.

[15] S. Rajaprasad and P. Chalapathi, "Factors Influencing Implementation of OHSAS 18001 in Indian Construction Organizations: Interpretive Structural Modeling Approach," Safety and Health at Work, vol. 6, pp. 200-205, 2015.

[16] W. Wu, C. Yang, J. Chang, P. Chateau, and Y. Chang, "Risk Assessment by Integrating Interpretive Structural Modeling and Bayesian Network, Case of Offshore Pipeline Project," Reliability Engineering and System Safety, vol. 142, pp. 515-524, 2015.

[17] V. Bañuls, M. Turoff, and S. R. Hiltz, "Collaborative Scenario Modeling in Emergency Management Through Cross Impact," Technological Forecasting \& Social Change, vol. 80, pp. 1756-1774, 2013.

[18] M. Turoff, A. Hendela, M. Chumer, X. Yao, J. Konopka, S. R. Hiltz, et al., "Gaming Emergency Preparedness," in 39th Annual Hawaii International Conference on System Sciences, HICCS 2006, Kauai, HI, 2006.

[19] N. E. Duncan and P. Wacky, "Scenarios Designed to Improve Decision Making," Strategy and Leadership, vol. 22, pp. 18-25, 46, 1994.

[20] L. Fahey, "Scenario Learning," Management Review, vol. 89, pp. 29-34, 2000.

[21] I. Wilson, "From Scenario Planning to Strategic Action," Technological Forecasting and Social Change, vol. 2000, pp. 23-29, 2000.

[22] P. Schoemaker, "Scenario Planning: A Tool for Strategic Thinking," Sloan Management Review, vol. 36, pp. 25-40, 1995.

[23] E. K. Clemons, "Using Scenario Analysis to Manage the Strategic Risks if Reengineering," Sloan Management Review, vol. 1995, pp. 61-71, 1995.

[24] S. March and G. Smith, "Design and Natural Research on Information Technology," Decision Support Systems, vol. 15, pp. 251-266, 1995.

[25] V. Vaishnavi and B. Kuechler. (2004, 4 August 2007). Design Research in Information Systems. Available: http://www.isworld.org/Researchdesign/drisISworld.ht m

[26] J. Mingers, "Combining IS Research Methods: Towards a Pluralist Methodology," Information Systems Research, vol. September 2001, pp. 240-259, 2001.

[27] J. Nunamaker, M. Chen, and T. Purdin, "Systems Develpoment in Information Systems Research," Journal of Management Information Systems, vol. 7, pp. 89-106, 1991.
[28] H. Linstone and M. Turoff, "Delphi: A Brief Look Backward and Forward," Technological Forecasting \& Social Change, vol. 2011, pp. 1712-1719, 2011.

[29] H. Linstone and M. Turoff, The Delphi Method: Techniques and Applications. Reading, MA: AddisonWesley, 1975.

[30] S. Brady, "Utilizing and Adapting the Delphi Method for Use in Qualitative Research," International Journal of Qualitative Methods, vol. 14, pp. 1-6, 2015.

[31] D. Thorleuchter and D. vandenPoel, "Quantitative Cross Impact Analysis With Latent Semantic Indexing," vol. 41, pp. 406-411, 2014.

[32] T. Gordon, "Cross Impact Method," ed. New York, NY: United Nation University Millennium Project, 1994, p. 21.

[33] C. Valmohammadi and S. Dashti, "Using Interpretive Structural Modeling and Fuzzy Analytical Process to Identify and Prioritize the Interactive Barriers of ECommerce Implementation," Information \& Management, vol. 53, pp. 157-168, 2015.

[34] M. Huega, V. Bañuls, and M. Turoff, "A CIA-ISM Scenario Approach for Analyzing Complex Cascading Effects in Operational Risk Management," Engineering Applications of Artificial Intelligence, vol. 46, pp. 289302, 2015.

[35] M. Turoff, V. Bañuls, L. Plotnick, and S. R. Hiltz, "Development of a Dynamic Scenario Model for the Interaction of Critical Infrastructures," in 11th International ISCRAM Conference, University Park, PA, 2014, pp. 414-423.

[36] M. Turoff, V. Bañuls, L. Plotnick, S. R. Hiltz, and M. Huega, "Collaborative Evolution of a Dynamic Scenario Model for the Interaction of Critical Infrastructures," in 12th International Conference on Information Systems for Crisis Response and Management, Kristiansand, Norway, 2015, p. 8.

[37] N. Dalkey, "An Elementary Cross Impact Model," in The Delphi Method: Techniques and Applications, $\mathrm{H}$. Linstone and M. Turoff, Eds., 1 ed Reading, MA: Addison-Wesley Publishing Company, 1975, p. 620.

[38] K. Herrmann, "The Comprehensive ICF Core Sets for Spinal Cord Injury from the Perspective of Occupational Therapists: A Worldwide Validation Study Using the Delphi Technique," Spinal Cord, vol. 49, pp. 600-613, 2011.

[39] PlanNYC, "A Stronger, More Resilient New York," O. o. t. M. o. t. C. o. N. York, Ed., ed. New York, NY, 2013, p. 445.

[40] A. Henry, "Developing a Business Continuity Plan," Rural Telecommunications, vol. 25, pp. 14-20, 2006.

[41] R. Benbunan-Fich, "Using Protocol Analysis to Evaluate the Usability of a Commercial Website " Information \& Management, vol. 39, pp. 151-163, 2001.

[42] C. Kobrak, "The Concept of Reputation in Business History," Business History Review, vol. 87, pp. 763-786, 2013. 